\title{
COMBATE EFECTIVO DE LOS DELITOS CONTRA LA BIODIVERSIDAD EN MÉXICO COMO UNA HERRAMIENTA DE CONSERVACIÓN DE LA BIODIVERSIDAD
}

\author{
Angel Daen Morales Garcia \\ Jonatan Job Morales Garcia \\ Biofutura A.C., MÉXICO
}

Resumen: La presente obra analiza la tutela de la biodiversidad por parte del Derecho penal en México y la efectividad de las instituciones gubernamentales encargadas de investigar, perseguir, procurar y administrar justicia ambiental en especifico de los delitos contra la biodiversidad del orden Federal. Los resultados dan a conocer los principales problemas en la procuración e impartición de justicia ambiental en México enfocada en los delitos contra la biodiversidad, concluyendo que existen errores substanciales (Estructura inadecuada de los tipos penales ambientales que tutelan a la biodiversidad) y adjetivos (Inadecuada garantía de acceso a la justicia en el procedimiento penal ambiental) en el marco normativo ambiental mexicano, aunado a una apatía generalizada por parte de los servidores públicos de las Instituciones ambientales, que en conjunto impiden la funcionalidad de la tutela penal de la biodiversidad, siendo necesario la participación proactiva de la ciudadanía en el combate a los ilícitos ambientales así como realizar adecuaciones en el marco jurídico mexicano a fin de contar con los elementos normativos para tener acceso a una verdadera justicia ambiental enfocada en la conservación de la biodiversidad.

Palabras clave: Justicia, Biodiversidad, Desarrollo sostenible, Conservación, Delitos ambientales.

Abstract: The present work analyzes the biodiversity protection by the Criminal Law in Mexico and the effectiveness of government institutions responsible for investigating, prosecuting, procuring and administering justice regarding biodiversity crimes pertaining to the Federal order. The results of this analysis make known the main problems in the administration and enforcement of environmental justice in Mexico focused on crimes against biodiversity concluding that exist substantial errors (Inadequate structure of environmental penal types that protect the biodiversity) and adjectives (Inadequate formulation of the justice access guarantee in the environmental criminal procedure) in the Mexican environmental regulatory system, as well as a government institutional apathy which prevents the effective functionality of the penal protection to the biodiversity, for that reason it is necessary the proactive citizen participation to confront environmental crimes, also it is jmportant realized adjustments in the Mexican legal framework to having regulatory elements to have a true access to environmental justice focused on biodiversity conservation.

Key words: Justice, Biodiversity, Sustainable development, Conservation, Environmental crimes. 


\section{I.- Introducción.}

La biodiversidad se encuentra intrínsecamente ligada al bienestar social y a la salud ecosistémica, brinda una gama amplia de servicios ecosistémicos que marcan no solo la estabilidad económica, ambiental y social de un pueblo, sino la subsistencia de la vida en el planeta tierra. Pese a los servicios esenciales que la biodiversidad suministra, actualmente las tasas de crecimiento poblacional, la marginación, la contaminación, el neoliberalismo y el capitalismo entre otros factores hacen que disminuya la biodiversidad a niveles alarmantes. La perdida de biodiversidad es uno de los pilares de la crisis ambiental que atravesamos, y esta crisis, se ha convertido en el principal reto que enfrenta la humanidad en el siglo XXI.

Al situar a México en relación a su biodiversidad, es importante analizar que de acuerdo a Ceballos, Salazar, List, Pacheco y Santos (2006) México es uno de los países con mayor diversidad biológica del planeta, es uno de los tres países con mayor biodiversidad del mundo, junto con Brasil e Indonesia, estos y otros 10 países en conjunto mantienen alrededor del $70 \%$ de todas las variedades de plantas, animales y microorganismos de la tierra y han sido llamados países megadiversos (Ceballos, 2008).

Empero, esta riqueza biológica se encuentra seriamente amenazada, Butchart et al. (2010) mencionan que la biodiversidad global se encuentra en disminución, actualmente estamos atravesando una crisis ambiental que representa uno de los principales problemas mundiales contemporáneos, en cuyos ejes de esta crisis la pérdida de biodiversidad representa la piedra angular. Chapin III (2000), considera que actualmente estamos atravesando la sexta extinción masiva en la historia del planeta tierra y la primera causada por una especie biológica, el humano, esta especie ha generado un grave deterioro en el planeta incluso ha contaminado el espacio exterior. De acuerdo a Dirzo et al. (2014), desde 1500 se han extinto 322 especies de vertebrados y las poblaciones de las especies restantes se encuentran en declive, steffen, W., Grinevald, J., Crutzen, P. y Mcneill, J. (2011) consideran que la huella humana sobre el medio ambiente global es tan grande que rivaliza con las grandes fuerzas de la naturaleza en el funcionamiento del planeta tierra, lo que ha dado pauta a la creación de una nueva época en la historia del planeta tierra, el antropoceno.

La extinción masiva de especies ha generado una preocupación mundial, esta preocupación forma parte de los elementos de origen del derecho ambiental como una herramienta para proteger a la biodiversidad. Empero, tras analizar la eficacia de los servidores públicos de las instituciones gubernamentales asociados a la justicia ambiental en México, el panorama que enfrentamos es grave, estas instituciones han fracasado en su función de ser una herramienta útil para la conservación. México se encuentra en un estado de necesidad de 
tutelar eficientemente a la biodiversidad a través del sistema de justicia penal, por lo que es necesario establecer cambios normativos y fortalecer la participación ciudadana en la lucha contra los delitos que afecten a la biodiversidad a fin de garantizar el derecho humano al acceso a la justicia ambiental y la conservación de la biodiversidad.

\section{II.- Derecho, medio ambiente y biodiversidad.}

A finales del siglo XX se ha ido consolidando el derecho humano a un medio ambiente sano enmarcándose en diversos instrumentos del derecho internacional, entre los instrumentos normativos más sobresalientes asociados al derecho ambiental y la biodiversidad, sobresalen los siguientes: (Tabla 1).

\section{Tabla 1. Principales instrumentos internacionales con nexos directos con la biodiversidad en México.}

\begin{tabular}{|c|c|c|}
\hline Instrumento normativo & $\begin{array}{l}\text { Año de } \\
\text { creación }\end{array}$ & Categoría \\
\hline $\begin{array}{l}\text { Convención entre los Estados Unidos } \\
\text { Mexicanos y los Estados Unidos de América } \\
\text { para la Protección de Aves Migratorias y de } \\
\text { Mamíferos Cinegéticos }\end{array}$ & 1936 & $\begin{array}{l}\text { No } \\
\text { vinculc }\end{array}$ \\
\hline $\begin{array}{llll}\text { Convención internacional para la } \\
\text { reglamentación de la caza de la ballena. }\end{array}$ & 1946 & Vincl \\
\hline $\begin{array}{l}\text { Declaración Universal de los Derechos } \\
\text { Humanos }\end{array}$ & 1948 & $\begin{array}{l}\text { No } \\
\text { vincul }\end{array}$ \\
\hline $\begin{array}{l}\text { Convención Relativa a los Humedales de } \\
\text { Importancia Internacional Especialmente } \\
\text { como Hábitat de Aves Acuáticas. }\end{array}$ & 1971 & Vincl \\
\hline $\begin{array}{l}\text { Declaración de las Naciones Unidas sobre el } \\
\text { Medio Ambiente. }\end{array}$ & 1972 & $\begin{array}{l}\text { No } \\
\text { vinculante }\end{array}$ \\
\hline $\begin{array}{l}\text { Convención sobre el Comercio Internacional } \\
\text { de Especies Amenazadas de Fauna y Flora } \\
\text { Silvestres, CITES. }\end{array}$ & 1973 & Vinculante \\
\hline $\begin{array}{l}\text { Protocolo adicional a la Convención } \\
\text { Americana sobre Derechos Humanos en } \\
\text { materia de derechos económicos, sociales y } \\
\text { culturales "Protocolo de San Salvador". }\end{array}$ & 1988 & Vinculante \\
\hline $\begin{array}{l}\text { Conferencia de las Naciones Unidas sobre el } \\
\text { Medio Ambiente y el Desarrollo. }\end{array}$ & 1992 & $\begin{array}{l}\text { No } \\
\text { vinculc }\end{array}$ \\
\hline Convenio sobre la Diversidad Biológica. & 1992 & Vinculante \\
\hline
\end{tabular}




\begin{tabular}{|l|l|l|l|}
\hline Convención Interamericana para la & 1996 & Vinculante \\
Protección y Conservación de las Tortugas & & \\
Marinas & & & \\
\hline
\end{tabular}

En el derecho interno, la base del derecho ambiental se consagra en el artículo 40., párrafo quinto de la Constitución Política de los Estados Unidos Mexicanos (CPEUM), adicionado el 28 de junio de 1999, este párrafo reconoce el derecho humano a un medio ambiente sano para el desarrollo y bienestar. Los servicios ecosistémicos que brinda la naturaleza repercuten en el bienestar supraindividual, por lo que los elementos bióticos y abióticos son considerados de interés social y están enmarcados en la CPEUM y tienden a regularse a través de disposiciones complementarias o secundarias del orden público a través del manejo, cuidado, protección, restauración y conservación de la biodiversidad para preservar y mantener dicho interés. El desarrollo sostenible, la protección al ambiente, conservación, preservación y la restauración del equilibrio ecológico como elementos establecidos en la CPEUM, interpretados de manera sistemática son ejes rectores y principios que establecen en un ámbito dogmático y orgánico la protección del derecho de las personas a un medio ambiente sano para su desarrollo y bienestar, si bien el estado no define de manera concreta y específica cómo es que ha de darse dicha protección, precisamente la definición de su contenido se hace con una interpretación sistemática, coordinada y complementaria de los ordenamientos que emanen de los tres poderes de la unión.

\section{III.- La perdida de biodiversidad en México}

Existe una interdependencia entre los elementos bióticos y abióticos que conforman un ecosistema, en el cual, cada uno tiene una función biológica en específico, y en conjunto forman parte del tejido de la vida, De acuerdo a sarukhán, J., Carabias, J. Koleff, P. y Urquiza, T. (2012), todos los animales y plantas dotan de bienes y servicios ecosistémicos que incluyen la provisión de bienes básicos, regulación, soporte y cultura. Esto hace que la pérdida de biodiversidad afecte directamente el desarrollo humano y derechos asociados al ambiente, aunado a lo anterior, el enfoque de las capacidades desarrollado por Nussbaum (2000) sugiere que toda nación reconozca a los animales como sujetos de justicia política y se recoja el compromiso de que los demás animales sean tratados como seres de derecho a una existencia digna, por lo que atentar contra la biodiversidad no solo nos afecta como especie, sino que en el caso de la fauna, se afectan derechos de los demás animales.

En México, la huella de la especie humana ha generado un impacto ambiental sin precedentes perdiendo especies de su medio silvestre, la 
SEMARNAT refiere a través de la norma oficial mexicana NOM-059SEMARNAT-2010 como especies probablemente extintas en el medio silvestre a 19 aves, 11 mamíferos, 13 peces y 6 plantas. En el caso de la fauna, de acuerdo al Programa Sectorial de Medio Ambiente y Recursos Naturales, PROMARNAT (2013) los grupos con más especies en el país en riesgo son los reptiles con $54.4 \%$, aves $33.5 \%$, mamíferos $45.2 \%$, anfibios $53.7 \%$ y peces $7.5 \%$, la biodiversidad mexicana se encuentra amenazada, por lo que es imperante instaurar mecanismos adecuados para su conservación.

\section{IV.- Necesidad de la tipificación de conductas que transgreden a la biodiversidad.}

Para Ferrajoli (2007), el Derecho penal se legitima y se justifica solamente si es capaz de lograr un doble efecto: (a) prevenir la comisión de conductas delictivas y (b) prevenir la aplicación de sanciones informales, a través de la venganza y las demás formas de violencia extrainstitucional que pueden darse en ausencia de una institucionalidad penal encargada de procesar y, en su caso, sancionar las conductas delictivas, por lo que el Derecho penal, afirma Mir Puig (1994), debe de asegurar la protección efectiva de todos los miembros de la sociedad, ha de tender a la prevención de delitos, entendidos como aquellos comportamientos que los ciudadanos estimen dañosos para sus bienes jurídicos, y que a través del proceso legislativo así se establezca, para Hassemer (1984), la conducta humana solamente puede ser injusto punible si lesiona un bien jurídico, siendo importante agregar la puesta del peligro del bien jurídico para que la conducta sea punible, esta teoría manifiesta necesidades e intereses del sistema social, el cual incluye la lesión o peligro de lesión al bien tutelado y que este tenga una repercusión social que trasgreda las disposiciones normativas penales. De acuerdo a Silva (1992), la funcionalidad social del Derecho penal como perspectivas empíricas son; ético-sociales, simbólicos y de satisfacción de psicología social. Los objetivos, finalidades y funcionalidades del derecho penal ambiental deben de tener un carácter concurrente en la conservación de la biodiversidad, esta interrelación cuenta con un sustento en un estado de necesidad apremiante a nivel planetario, ya que la propia subsistencia de la especie humana se encuentra en peligro. Los instrumentos normativos pertenecientes a ramas diversas del Derecho penal (Derecho administrativo, Derecho civil, Derecho mercantil, entre otros) si bien tienen incidencia en temas relacionados con la biodiversidad, estas ramas del Derecho no cuentan con la capacidad de proteger adecuadamente a la diversidad biológica ya que tienen una baja 
efectividad en su campo de acción en México, 1 y debido a la grave presión a la que se encuentra sometida la diversidad biológica es por lo que es necesario la intromisión del Derecho penal como una herramienta para la conservación, y es aquí donde se legitima el principio de ultima ratio ya que los demás medios jurídicos para la conservación de la biodiversidad resultan ineficaces para tal efecto, ya que en caso contrario, la biodiversidad se enfrentaría a un grave colapso.

\section{V.- Panorama de México ante los delitos contra la biodiversidad.}

Las causas de pérdida de biodiversidad son diversas, sin embargo, de acuerdo a Wood, A., Stedman-Edwards, P. y Mang J. (1998) estas causas se pueden englobar en dos grandes rubros: las inmediatas y las estructurales, las primeras surgen como consecuencia de las segundas. Dentro de estas causales, el trafico ilicito de biodiversidad ocupa el segundo lugar como amenaza para la vida silvestre (Nadal, L., Carmona, A., y Trouyet, M. (2013). A nivel mundial, United Nations Office on Drugs and Crime UNODC (2012), establece que los delitos contra la vida silvestre y los bosques son una de las formas más redituables de delincuencia organizada, después de la venta ilegal de drogas y el tráfico de armas de fuego y municiones.

Dimensionar la problemática mundial de la pérdida de biodiversidad y el tráfico ilícito de vida silvestre es sumamente difícil, debido a su naturaleza ilícita, resulta imposible definir la extensión precisa del comercio ilegal de vida silvestre, la Organización Internacional de Policía Criminal (INTERPOL) calcula que el contrabando de vida silvestre tiene un valor hasta de diez miles de millones de dólares anuales, ubicándose en el tercer lugar de importancia en tráfico ilegal, solo superado por el tráfico de drogas y armas (CCA, 2005), el estudio de Haken (2011) se establece que el tráfico ilícito de vida silvestre comprende el cuarto mayor comercio ilegal a nivel mundial después de las drogas, el tráfico de personas y los productos falsificados. El tráfico ilícito de vida silvestre genera una gran perdida de biodiversidad, para el caso de México, si bien existen políticas públicas asociadas a la conservación y la justicia ambiental, estas no han sido eficientes debido principalmente a que las instituciones gubernamentales ambientales encargadas en la impartición de la justicia ambiental tienen una participación deficiente teniendo como resulłado impunidad y perdida de la diversidad biológica. En promedio entre el año 2010 y 2012 se

\footnotetext{
I Esta problemática no es única de México, ya que en países Europeos se ha apuntado la supuesta "insuficiencia" del Derecho administrativo y de otros mecanismos jurídicos diversos a la vía penal, véase Ropero, J. (2006), "El «medio ambiente» como bien jurídico susceptible de protección jurídico penal", en: Revista Letras Jurídicas, Vol. 13, Xalapa, Centro de Estudios sobre Derecho, Globalización y Seguridad, pp. 2-16, (citando a: Vercher, A., "Consejo de Europa y protección penal del medio ambiente", en: La Ley, Año: 1991, No. 2, pp. 1070 y ss.)
} 
iniciaron 1981,676.6 averiguaciones previas por la probable comisión de delitos en México, de los cuales en promedio 1,332.6 son delitos contra la biodiversidad lo que representa el 0.067 por ciento del total de delitos. En tres años comprendidos de 2010 a 2012 de cada 100 delitos que se cometen en México solo se denuncian 6.6, tomando estos índices aplicados a los delitos contra la biodiversidad, de los 6.6 que se denuncian $(1,332.6)$ el 4.88 se consigna por parte del Ministerio Público poniéndose a disposición de un juez federal, y solamente el 0.32 por ciento recibe una sentencia condenatoria por delitos contra la biodiversidad. El fenómeno delictivo contra la biodiversidad entendiéndolo desde la averiguación previa en los años 2009 al 2012 en México de 100 denuncias por posibles hechos delictivos contra la biodiversidad, solo 4.8 cuentan con una sentencia condenatoria por un juez federal (tabla 2), aunado que dicha sentencia puede ser recurrible a través del recurso de apelación.

Tabla 2. Impunidad Ambiental asociada a los delitos contra la biodiversidad.

\begin{tabular}{l|l|l|l|}
\hline Datos & 2010 & 2011 & 2012 \\
\hline $\begin{array}{l}\text { Cifra negra (\%). } \\
\text { Total de averiguaciones previas iniciadas } \\
\begin{array}{l}\text { por la probable comisión de delitos } \\
\text { denunciados. }\end{array}\end{array}$ & 92.00 & 96.10 & 92.10 \\
\hline $\begin{array}{l}\text { Averiguaciones previas iniciadas por la } \\
\text { probable comisión de delitos contra la } \\
\text { biodiversidad. }\end{array}$ & 1,253 & $1,894,296$ & $2,196,247$ \\
$\begin{array}{l}\text { Personas consignadas por la comisión de } \\
\text { delitos contra la biodiversidad. }\end{array}$ & 892 & 1,054 & 1,016 \\
\hline $\begin{array}{l}\text { sentencia condenatoria por la comisión de } \\
\text { delitos contra la biodiversidad. }\end{array}$ & 64 & 72 & 59 \\
\hline
\end{tabular}

Fuente: Centro de Investigación para el Desarrollo, A.C. CIDAC (2016), INFOMEX (2016), Estadísticas judiciales en materia penal del Instituto Nacional de Estadística y Geografía INEGI (s.f.).

La impunidad de los ilícitos ambientales imposibilita la tutela efectiva de la biodiversidad, causando una desestabilidad socio ambiental que incluye la pérdida de vidas humanas (ECOSOC, 2013). Si bien los delitos contra la biodiversidad se dimensionan a nivel mundial con el narcotráfico y el tráfico de armas, al extrapolar y cuantificar estos tres ilícitos en el ámbito delictivo nacional de individuos con una sentencia condenatoria en primera instancia por la comisión de delitos en México obtenemos una cifra desigual, de acuerdo al Instituto Nacional de Estadística y Geografía (INEGI) en un periodo de 4 años comprendidos de 2009 al 2012 se arrojan los siguientes datos (gráfica 1). 
Fuente: Impunidad Ambiental asociada a los delitos contra la biodiversidad. Fuentes: Centro de Investigación para el Desarrollo, A.C. CIDAC (2016), INFOMEX (2016), Estadísticas judiciales en materia penal del INEGI (s.f.).

El número de personas con una sentencia condenatoria en primera instancia al yuxtaponer con referencia a la incidencia mundial antes mencionada, analizamos que existe una cifra baja referente a la sanción de los delitos contra la biodiversidad y la justicia ambiental, y que sumado a los índices de impunidad antes señalados, se refleja la ineficiencia del Derecho penal como herramienta de conservación de la biodiversidad. Al analizar el total de sentencias (condenatorias y absolutorias) en materia de delitos contra la biodiversidad a través de las estadísticas judiciales en materia penal del INEGI en un periodo de 16 años comprendido de 1997 al 2012, los datos son alarmantes, ya que de 1997 al 2007 no existió ningún registro referente a alguna sentencia relacionada con este tipo de delitos, posteriormente del 2008 al 2012 hubo un total de 278 individuos sentenciados por cometer ilícitos contra la biodiversidad, siendo una cifra demasiado baja en comparación con su dimensión socioambiental (Gráfica 2 y tabla 3).

Fuente: Impunidad Ambiental asociada a los delitos contra la biodiversidad. Fuentes: Centro de Investigación para el Desarrollo, A.C. CIDAC (2016), INFOMEX (2016), Estadísticas judiciales en materia penal del INEGI (s.f.).

\section{Tabla 3. Delitos contra la biodiversidad en México 1997-2012.}

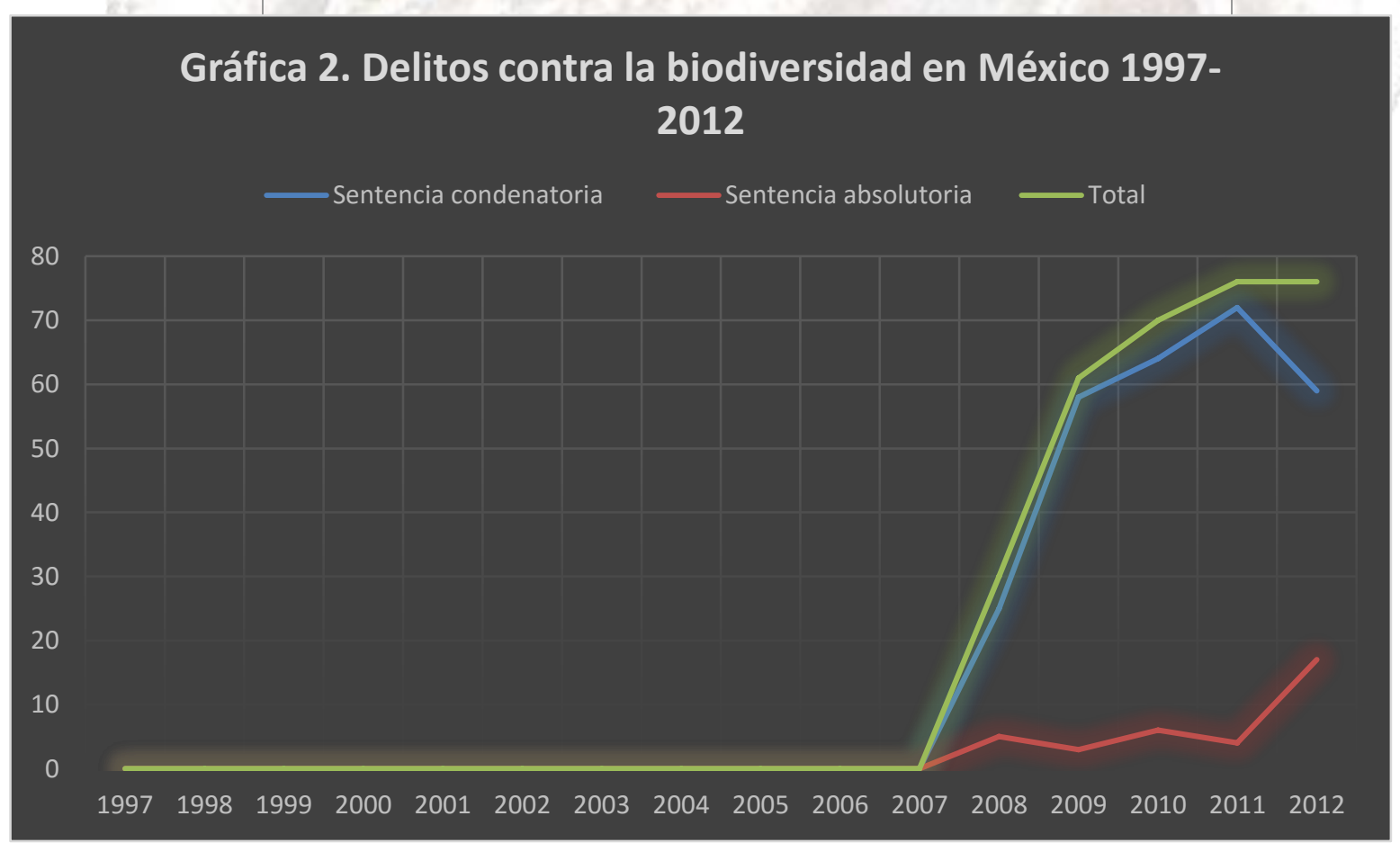

1997

0

0

0 


\begin{tabular}{|l|l|l|l|}
\hline 1998 & 0 & 0 & 0 \\
\hline 1999 & 0 & 0 & 0 \\
\hline 2000 & 0 & 0 & 0 \\
\hline 2001 & 0 & 0 & 0 \\
\hline 2002 & 0 & 0 & 0 \\
\hline 2003 & 0 & 0 & 0 \\
\hline 2004 & 0 & 0 & 0 \\
\hline 2005 & 0 & 0 & 0 \\
\hline 2006 & 0 & 0 & 0 \\
\hline 2007 & 0 & 0 & 0 \\
\hline 2008 & 25 & 5 & 30 \\
\hline 2009 & 58 & 3 & 61 \\
\hline 2010 & 64 & 6 & 70 \\
\hline 2011 & 72 & 4 & 76 \\
\hline 2012 & 59 & 17 & 76 \\
\hline
\end{tabular}

Fuente: Estadísticas judiciales en materia penal del INEGI ( s.f.).

Esta deficiencia del sistema de justicia ambiental para la protección de la biodiversidad es resultado de una multiplicidad de factores jurídicos y meta jurídicos que genera una brecha en el acceso a la justicia ambiental, estos factores se traducen en errores de fondo en la construcción de los tipos penales, errores de forma en el sistema procesal penal ambiental y factores meta jurídicos los cuales son fenómenos sociales que afectan a la biodiversidad como la corrupción que llega a ser un elemento secundario de los ilícitos contra la biodiversidad, el vínculo existente con la delincuencia organizada en la comisión de delitos ambientales o la falta de interés de las institúciones gubernamentales (Zimmerman, 2003).

\section{VI.- Los delitos contra la biodiversidad en el sistema jurídico mexicano.}

En el siglo XX, la protección de la biodiversidad en México con carácter coercitivo y punitivo por el derecho penal tiene como antecedente la creación de la Ley General del Equilibrio Ecológico y la Protección al Ambiente que se publicó en el Diario Oficial de la Federación el 28 de Enero de 1988 que establecía en su capítulo VI del título sexto los delitos del orden Federal, empero, los tipos penales descritos de los numerales 183 al 187 no tenían una relación directa con conductas que afectaran a la biodiversidad, posteriormente el 13 de Diciembre de 1996 se derogaron esos artículos, y mediante reforma al Código Penal Federal (CPF) en la misma fecha a fin de tener una concentración de los delitos 
en un solo marco normativo, se adicionó el título vigésimo quinto, que en su capítulo único se denominaba delitos ambientales, y posteriormente, el 6 de Febrero de 2002 se realizaron en el mismo ordenamiento jurídico reformas a los artículos 60, segundo párrafo, 414 , $415,416,417,418,419,420,421,422$ y 423 , así mismo se instrumentaron los artículos 420 Bis, 420 Ter y 420 Quater, posteriormente, el 8 de Febrero de 2006 se adiciono la fracción II bis al artículo 420 del mismo ordenamiento legal quedando establecidos los tipos penales contra la biodiversidad que actualmente rigen el sistema penal ambiental en el CPF en su Capitulo Segundo del Título Vigésimo Quinto Delitos Contra el Ambiente y la Gestión Ambiental de los numerales 417 al 420 bis.

Si bien existen disposiciones que tipifican conductas contra la biodiversidad en el marco normativo mexicano desde hace mas de 27 años, estas disposiciones no han tenido un impacto real en la conservación de la biodiversidad. En septiembre de 1997 se encontraban solamente 17 expedientes de averiguación previa por delitos ambientales (Cossío, J., Meza, E. 2013) lo que demuestra una ineficacia al combate de estos delitos, y por ende una perdida de biodiversidad a niveles críticos.

\section{VII.- Problemática de fondo en los delitos contra la biodiversidad. \\ 1.- Estructura de los delitos contra la biodiversidad: Sus problemas y alcances.}

Las construcciones de los tipos penales deben de tener una estructura lógica semántica que exprese una carga deontológica expresada mediante la estructuración bicondicional del supuesto jurídico y la consecuencia jurídica, de acuerdo a Alvarado (2011), el supuesto jurídico recibe el nombre de tipo y la consecuencia jurídica el de punibilidad, por lo que ninguno de los dos componentes es una norma completa sino parte de la misma, las estructuras de los tipos penales deben de ser adecuados al contexto normativo y los principios vectores que dan el sustento básico de la ley penal, ya que el tipo penal debe de tener elementos necesarios para la determinación de la conducta prohibitiva $u$ ordenada, esto es el principio de legalidad el cual engloba el principio de exacta aplicación y el principio de reserva de ley, el primero se enmarca en el artículo 14 de la CPEUM en su párrafo tercero; "En los juicios del orden criminal queda prohibido imponer, por simple analogía, y aún por mayoría de razón, pena alguna que no esté decretada por una ley exactamente aplicable al delito de que se trata" este Derecho Humano obliga a la autoridad legislativa a emitir normas penales donde se estipule de manera clara la conducta reprochable y la consecuencia jurídica por la comisión de una conducta ilícita para que el juzgador tenga una objetividad real, lo que da una garantía de certidumbre jurídica referente a la aplicación del Derecho penal con todos los elementos penales de manera expresa, y el segundo; el principio de reserva de ley, consiste en la remisión que se hace 
expresamente en la CPEUM sobre la facultad única del Congreso de la Unión establecida en el numeral 73, fracción XXI para expedir la legislación que establezca los delitos y las faltas contra la Federación y las penas y sanciones que por ellos deban imponerse, así como legislar en materia de delincuencia organizada, esto bajo el principio de división de poderes del sistema político mexicano, y que se faculta única y exclusivamente al Congreso de la Unión para legislar en materia penal.

Así mismo, el llamado principio de taxatividad o exigencia de un contenido concreto y unívoco en la labor de tipificación de la ley es un elemento esencial en la construcción de la norma penal. Es decir, que la descripción típica no debe ser vaga, imprecisa, abierta o amplia, al grado de permitir la arbitrariedad en su aplicación, pues para garantizar el principio de plenitud hermética en cuanto a la prohibición de analogía o mayoría de razón en la aplicación de la ley penal, ésta debe ser exacta, y no sólo porque a la infracción corresponda una sanción, pues sucede que las normas penales deben cumplir una función motivadora en contra de la realización de delitos, para lo que resulta imprescindible que las conductas punibles estén descritas con exactitúd y claridad, pues no se puede evitar aquello que no se tiene posibilidad de conocer con certeza. En consecuencia, Ferreres (2002) establece que el mandato de taxatividad supone la exigencia de que el grado de determinación de la conducta típica sea tal, que lo que es objeto de prohibición pueda ser conocido sin problemas por el destinatario de la norma.

Sentado lo anterior procede referirse a otra derivación de la garantía de legalidad en materia penal, que es la referente a la llamada reserva de ley, consistente en que la facultad para fijar e imponer las penas por las faltas y delitos a nivel federal, corresponde en exclusiva al Congreso de la Unión, de conformidad con el artículo 73 de la CPEUM, que en su fracción XXI, establece que por mandato constitucional es facultad indelegable del Congreso de la Unión, establecer los delitos federales y las penas, lo que debe hacer a través de leyes en sentido formal y material, y ello es necesario para garantizar a los particulares la certeza jurídica en cuanto a las conductas cuya comisión puede traer consigo la privación y restricción de la libertad individual.

Resulta entonces que la reserva de ley en materia penal constituye un requisito inherente a la tarea de definición de las distintas conductas que se estiman merecedoras de sanción, lo que por imperativo constitucional es atribuido en exclusiva al legislador democrático con carácter privatista, pues salvo el caso de facultades extraordinarias, conforme a lo dispuesto en el artículo 29 constitucional, tal facultad no puede ser válidamente delegada, y de hacerse así, la ley que se emitiera estaría viciada de inconstitucionalidad. 
En esos términos, el principio de reserva de ley implica que todas las normas que establezcan los delitos y sus penas deben contenerse en una ley en sentido formal y material, producto de la discusión de una asamblea democrática, de modo que no pueden crearse ni modificarse sin una iniciativa o una reforma cuya tramitación debe ser acorde con los procedimientos legislativos correspondientes, lo que constituye una medida indispensable para dar certeza al Derecho penal en tanto que éste incide en la libertad de los individuos. Por otra parte, el principio de legalidad que rige la materia penal también impide que el juez asuma funciones regulatorias que van más allá de la función meramente aplicativa que le es propia, de modo que, en principio, todo el Derecho penal debe completarse en el momento legislativo sin conferir facultades a las instancias Jurisdiccionales 0 Ejecutivas, pues ello lesiona el principio de seguridad jurídica.

Bajo las características básicas de la estructura de los tipos penales, es importante analizar la problemática nacida desde la creación de los delitos contra la biodiversidad que en específico presenta el numeral 420 del CPF siendo importante enunciar que este artículo presenta elementos que no se enuncian en alguna disposición legislativa sino en instrumentos distintos como normas oficiales mexicanas. A continuación se enuncian a través de la teoría de la norma de Henrik (1951) los elementos normativos de condiciones de aplicación de la norma que es el conjunto de circunstancias que han de darse para que la norma sea cumplida, alguno de estos elementos son el eje central de la problemática.

Condiciones de aplicación del artículo 420 del CPF:

Especie de flora o fauna silvestres, terrestres o acuáticas en veda, considerada endémica, amenazada, en peligro de extinción, sujeta a protección especial, o regulada por algún tratado internacional del que México sea parte.

Cuando se estipula "alguna especie de flora o fauna silvestre," existe la Ley General de Vida Silvestre que establece en su Artículo 3o. fracción XLIX lo siguiente:

...XLIX. Vida Silvestre: Los organismos que subsisten sujetos a los procesos de evolución natural y que se desarrollan libremente en su hábitat, incluyendo sus poblaciones menores e individuos que se encuentran bajo el control del hombre, así como los ferales

Por lo cual al realizar acciones del contenido del tipo penal como el traficar, capturar, poseer, transportar, acopiar, introducir al país 0 extraer algún ejemplar objeto de la prohibición, o dañar cualquier ejemplar de flora y fauna de vida silvestre constituye un delito contra la biodiversidad y se establecen todos los lineamientos de la estructura penal. 
Empero, los elementos normativos denominados terrestres o acuáticas en veda, considerada endémica, amenazada, en peligro de extinción, sujeta a protección especial no se estipulan en algún precepto legal o en un instrumento internacional vinculante, por lo cual se remiten a la NOM-059-SEMARNAT-2010, y a disposiciones normativas como las declaratorias de veda, que son ordenamientos normativos del poder Ejecutivo. La última condición de aplicación que establece el citado precepto es que se encuentre regulada por algún tratado internacional del que México sea parte, mencionados anteriormente.

El citado ordenamiento jurídico ha sido analizado por jueces y magistrados pertenecientes al Poder Judicial de la Federación y se han consagrado bajo tres criterios que si bien no tienen ninguno aun el carácter de general es importante analizarlos. En 2007 se estableció el primer criterio en la materia, de acuerdo a Cossío et al. (2013), los Ministros Cossío, Sánchez Cordero y Valls, sostuvieron al resolver el 28 de Noviembre de 2007 Amparo directo en revisión 886/2007, que el artículo 420 del Código Penal Federal, al no constituir una norma penal que se configure por elementos extralegales, no violaba lo dispuesto en el artículo 14 de la CPEUM. Este criterio fue reiterado al resolverse los amparos en revisión 51/2009, 74/2009, 1911/2009, 2004/2009 y 2082/2009. En el año 2009, el criterio de la Primera sala fue modificado al resolverse el amparo en revisión 2062/2009, en sesión del 13 de Mayo de 2010, ya que la mayoría considero que el citado artículo del Código Penal Federal si violaba los principios de reserva de ley y exacta aplicación previstos en el artículo 14 de la CPEUM, Este criterio prevaleció en los amparos en revisión 2230/2009, 85/2010, 147/2010 y 402/2010, sin que por las votaciones obtenidas fuera posible la emisión de las tesis necesarias para la constitución de jurisprudencia obligatoria, empero, la jurisprudencia utilizada en estos criterios era la siguiente Tesis 1a./J. 10/2006 y la Tesis XIII.P.A.21 P, emitidas en la Novena Época. El criterio sobre la inconstitucionalidad del artículo 420 fracción IV CPF versaba sobre las condiciones de aplicación, y en este razonamiento se estipulaba que la inconstitucionalidad en este numeral era parcial debido a que en su última parte condiciona que el ejemplar se encuentre regulado por un tratado internacional del que México sea parte. Ya en 2010 por tercera vez, la primera sala de la Suprema Corte de Justicia de la Nación cambio de postura y determino que los tipos contenidos específicamente en las fracciones II y IV del artículo 420 de CPF no constituyen "tipos penales en blanco" $y$, por ende, no violan el contenido del artículo 14 constitucional, en este mismo sentido comenta Cossío et al. (2013) que se resolvieron los juicios de amparo en revisión $582 / 2010,815 / 2010,828 / 2010,2938 / 2010,455 / 2011,643 / 2011$ y 500/2012. Este criterio es el que ha prevalecido al día de hoy, generado tesis de 
jurisprudencia y aisladas a fin de tener delitos contra la biodiversidad adecuados al sistema normativo mexicano. ${ }^{2}$

\section{1- Análisis del criterio actual.}

De acuerdo a Heine (1993), para el Derecho penal las consideraciones del ordenamiento jurídico-administrativo sobre los daños al ambiente son, en gran medida, imprescindibles, y se distinguen tres modelos con finalidades de protección muy diferentes y que plantean cuestiones distintas: 1.- El Derecho penal (especial) clásico absolutamente dependiente de la administración, 2.- El Derecho penal (común) relativamente dependiente de la administración y 3.- La regulación penal independiente de la administración. Derivado del ultimo criterio que sostiene la Suprema Corte de Justicia de la Nación en materia de delitos contra la biodiversidad, este se adecua al segundo modelo manejado por Heine, ya que da un carácter accesorio al Derecho administrativo para articular el Derecho penal con los lineamientos técnicos y científicos del Derecho ambiental no penal para integrar los elementos normativos de estos delitos, este criterio establece que es imposible describir en tipos penales todos los componentes de un ilícito ambiental punible, así que debe acudirse a elementos normativos que han de interpretarse con ayuda de criterios ofrecidos por leyes no penales, como consecuencia de la dependencia del Derecho ambiental de otras materias con disposiciones técnico científicas que pertenecen al campo de la ciencia, lo que hace que el Derecho penal por sí solo sea insuficiente para afrontar las exigencias que su regulación implica y exige una relación equilibrada entre el Derecho penal y la normatividad ambiental para ejercitar una adecuada función preventiva y sancionadora.

Así mismo, se establece que el bien jurídicamente tutelado por el artículo 420 fracción II del CPF es la eficacia de la orden de la autoridad administrativa derivada de la creación de normas oficiales mexicanas y que el Derecho penal tiene una protección reforzada sobre especies reguladas por el Derecho administrativo bajo algún estatus de protección.

El conflicto esgrimido por la Suprema Corte de Justicia de la Nación en la formulación de criterios de los delitos contra la biodiversidad divergen si estos tipos penales se apegan a los lineamientos normativos del bloque de constitucionalidad, o si carecen de los elementos de la norma penal (delitos en blanco), por lo que el criterio prevaleciente estipula que los delitos contra la biodiversidad no violan el principio de exacta aplicación de la norma penal al remitir a una normatividad no penal ambiental (Derecho administrativo) ya que no genera

2 Tesis 1a./J. $21 / 2012$ (9a.), Tesis 1a./J. 22/2012 (9a)Tesis 1a./J. 23/2012 (9a.), Tesis la. XXIX/2012 (9a.) Tesis 1a. XXX/2012 (9a.) Tesis 1a. XXVII/2012 (9a.), Tesis 1a. XXVIII/2012 (9a.), emitidas en la décima Época. 
indeterminación o inseguridad jurídica, y si bien se remiten a disposiciones no penales, esto no impide que se entienda perfectamente la conducta tipificada enfocada en la prohibición de realizar actividades antrópicas que afecten a ciertas especies, ya que las condiciones de aplicación del citado numeral que constituyen un elemento normativo de valoración no integra el núcleo de la prohibición, teniendo así una reserva relativa del tipo Penal, ya que en esta intervención del Derecho ambiental no penal se legitima un espacio de intervención limitado al Poder Ejecutivo que se deriva de una complementación técnica y científica, estos elementos normativos no penales no trasgrede el orden constitucional y por ende no viola el principio de reserva de ley.

Si bien prevalece el criterio antes referido desde el 2010, es de suma importancia mencionar que las actuaciones de algunos juzgados de distrito cuando conocen de delitos contra la biodiversidad, estos no se adecuan a lo establecido en el último criterio de la Suprema Corte de Juśticia de la Nación sobre la constitucionalidad de los delitos contra la biodiversidad, por lo que algunos jueces y magistrados del Poder Judicial de la Federación en las resoluciones que emiten violentan el bloque de constitucionalidad ambiental.

\section{VIII.- Problemática de forma en los delitos contra la biodiversidad.}

\section{1.- Los retos del acceso a la justicia ambiental}

El acceso a la justicia ha sido entendido como una garantía esencial del Estado Social Democrático de Derecho (Valencia, 2014), este derecho se puede rastrear de acuerdo a Martínez (1997), en la categoría de derechos civiles y políticos o también llamados de primera generación y establece una conditio sine qua non en relación con los derechos ambientales. El acceso a la justicia ambiental es un elemento central para lograr la protección ambiental y el desarrollo sostenible Comisión Económica para América Latina y el Caribe (CEPAL, 2013), y se encuentra consagrado en el Principio 10 de la Declaración de Rio sobre el Medio Ambiente y el Desarrollo.

En el sistema normativo mexicano se han reconocido derechos fundamentales ambientales, estableciendo un pluralismo jurídico para su protección y justicia donde se asientan los medios de defensa y recursos legales tanto en Derecho público como en Derecho privado debido a la naturaleza mixta e interdisciplinaria del Derecho ambientalpara que las personas puedan dirimir conflictos ambientales ante instancias jurisdiccionales nacionales y órganos internacionales.

En materia de justicia ambiental, Ibarra (2014) menciona que los delitos contra el ambiente se posicionan como uno de los principales problemas de México, el acceso a la justicia penal enfocado en la 
protección de la biodiversidad atraviesa una serie de dificultades en torno a su aplicación y tutela por parte del Estado ya que se presentan obstáculos normativos procesales y meta jurídicos en el subsistema de justicia ambiental penal que condicionan el acceso a la justicia.

\section{2.- Obstáculos normativos procesales.}

La protección efectiva de la biodiversidad requiere que los ciudadanos incorporen en sus hábitos cotidianos los patrones de conducta que deben prevalecer en la sociedad y hagan uso de su derecho a denunciar (Cossío, Sarukhán, Carabias \& Bolívar, 2014), de acuerdo a Nadal, Carmona y Touyet (2013) la denuncia ciudadana tiene un papel trascendental en la lucha contra el tráfico ilegal de vida silvestre y la conservación de la biodiversidad, por lo que las disposiciones normativas deben ser una herramienta eficaz para que las personas ejerzan su derecho al acceso a la justicia ambiental.

El principal obstáculo procesal que presentan las personas al momento de realizar la denuncia y movilizar el subsistema de justicia ambiental penal es referente a la situación jurídica con la que van a intervenir al momento de presentar la notitia criminis y su actividad en el procedimiento penal acusatorio. Esta problemática se relaciona con la figura del sujeto pasivo del delito, que al ser la propia biodiversidad y los servicios ecosistémicos, se rompe la visión individualista clásica del sistema penal y da pauta a la protección de intereses colectivos, difusos, supraindividuales, integrales y ecológicos por lo que cualquier individuo debe de tener la obligación y el derecho de salvaguardar la naturaleza a través de todos los medios jurisdiccionales que instaura el estado. Sin embargo, este derecho se encuentra violentado y limitado por la negativa procesal de reconocer a cualquier individuo como sujeto del procedimiento penal como victima, ofendido y coadyuvante en los delitos contra la biodiversidad, esto ha traído como consecuencia que el derecho penal no sea una herramienta eficaz para tutelar la biodiversidad, la paz social y la convivencia armónica.

Para dimensionar la conceptualización de la víctima en materia ambiental no solamente se debe de incluir al sujeto pasivo del delito, sino todo aquel que sufre las consecuencias de la comisión de un hecho delictivo (Fernández, 1995). Al analizar la figura de la victima en materia penal ambiental es importante referir que existe en México una normatividad especializa denominada Ley General de Victimas, esta disposición en su artículo 4 establece el concepto de victima de la siguiente manera:

Artículo 4. Se denominarán víctimas directas aquellas personas físicas que hayan sufrido algún daño o menoscabo económico, físico, mental, emocional, o en general cualquiera puesta en peligro o lesión a sus bienes jurídicos o derechos como consecuencia de la comisión de un 
delito o violaciones a sus derechos humanos reconocidos en la Constitución y en los Tratados Internacionales de los que el Estado Mexicano sea Parte.

Son víctimas indirectas los familiares o aquellas personas físicas a cargo de la víctima directa que tengan una relación inmediata con ella.

Son víctimas potenciales las personas físicas cuya integridad física o derechos peligren por prestar asistencia a la víctima ya sea por impedir o detener la violación de derechos o la comisión de un delito.

La calidad de víctimas se adquiere con la acreditación del daño o menoscabo de tos derechos en los términos establecidos en la presente Ley, con independencia de que se identifique, aprehenda, o condene al responsable del daño o de que la víctima participe en algún procedimiento judicial o administrativo.

Son víctimas los grupos, comunidades $u$ organizaciones sociales que hubieran sido afectadas en sus derechos, intereses o bienes jurídicos colectivos como resultado de la comisión de un delito o la violación de derechos.

Esta disposición en su último párrafo reconoce la figura de la victima en un rubro colectivo, sin embargo, excluye a las personas físicas. Violentando lo establecido en la Declaración sobre los principios fundamentales de justicia para las víctimas de delitos y del abuso de poder (1985).

En el Código Nacional de Procedimientos Penales (CNPP) el numeral 1,08 define a la víctima $U$ ofendido consagrándose de la siguiente manera:

Artículo 108. Víctima u ofendido

Para los efectos de este Código, se considera víctima del delito al sujeto pasivo que resiente directamente sobre su persona la afectación producida por la conducta delictiva. Asimismo, se considerará ofendido a la persona física o moral titular del bien jurídico lesionado o puesto en peligro por la acción u omisión prevista en la ley penal como delito.

En los delitos cuya consecuencia fuera la muerte de la víctima o en el caso en que ésta no pudiera ejercer personalmente tos derechos que este Código le otorga, se considerarán como ofendidos, en el siguiente orden, el o la cónyuge, la concubina o concubinario, el conviviente, los parientes por consanguinidad en la línea recta ascendente 0 descendente sin limitación de grado, por afinidad y civil, o cualquier otra persona que tenga relación afectiva con la víctima.

La víctima $u$ ofendido, en términos de la Constitución y demás ordenamientos aplicables, tendrá todos los derechos y prerrogativas que en éstas se le reconocen. 
De lo anterior podemos analizar que el Congreso Legislativo en este instrumento normativo no rebasa el individualismo del Derecho penal y deja de nuevo una laguna en la legitimación activa de cualquier ciudadano como victima y poder coadyuvar con el Ministerio Publico en los delitos contra la biodiversidad los cuales deben de tener una integración adecuada con los Derechos difusos, colectivos y ecológicos.

Otra disposición normativa que da el sustento del acceso a la justicia ambiental enfocado en ta conservación de la biodiversidad es el CPF, donde en su apartado denominado disposiciones comunes a los delitos contra el ambiente, articulo 421, en su ultimo parrafo, se establece lo siguiente:

(...) Se considerarán victimas con derecho a solicitar la reparación o compensación del daño ambiental y coadyuvar en el proceso penal, a las personas legitimadas en términos de lo dispuesto por la Ley Federal de Responsabilidad Ambiental.

Esta disposición nos remite a la Ley Federal de Responsabilidad Ambiental donde la base se establece lo siguiente referente a la victima en materia de delitos contra el medio ambiente.

Artículo 56.- Atento a lo dispuesto por el párrafo cuarto del artículo 40. de la Constitución Política de los Estados Unidos Mexicanos, se considerará víctima de los delitos contra el ambiente a toda persona habitante de la comunidad posiblemente afectada por el ilícito cuando se constituya como denunciante ante el Ministerio Público.

Este articulo representa un impedimento al acceso a la justicia ambiental, si bien en este numeral se considera a las personas físicas como victimas, el legislador cae en el error de delimitar en un orden territorial la afectación al bien jurídicamente tutelado, se ha referido que la afectación causada por delitos contra la biodiversidad es de naturaleza supraindividual y que no concierne solo a un individuo o grupo en especifico, la perdida de biodiversidad afecta no solo a una comunidad, sino a todo un país y al mundo entero, aunado a lo anterior, existen zonas biogeográficas del país donde no hay asentamientos humanos y que dejaría imposibilitado la facultad de constituirse como victima a cualquier individuo ambientalmente comprometido.

La eficacia de la defensa ambiental tiene una relación directa con los obstáculos que se presenten al individuo en la exigencia ante los órganos investigadores y jurisdiccionales del estado en materia de justicia ambiental, al no existir ni siquiera un reconocimiento formal al acceso a la justicia ambiental como derecho subjetivo establecido en las disposiciones penales adjetivas, (procesales) nos enfrentamos a una grave violación de Derechos Humanos al acceso a la justicia, este Derecho se ve coartado por el Estado al no establecer las modalidades 
de la defensa ambiental no solo de organizaciones de la sociedad civil - grupos y pueblos indígenas, sino de cualquier individuo, ya que representa un Derecho Humano.

\section{VIII.- Conclusión.}

El combate efectivo de los delitos contra la biodiversidad son una herramienta para la conservación, el éxito de la política criminal enfocado en la protección de la biodiversidad radica en realizar las adecuaciones en el marco normativo a fin de establecer los elementos necesarios para enfrentar los ilícitos contra la vida silvestre de manera idónea. En un ámbito sustantivo penal ambiental, es necesario impulsar el proceso legislativo de reforma al sistema normativo para de contar con una construcción idónea de los tipos penales ambientales que incluya el vínculo del tipo penal con la condición de aplicación y tener certeza jurídica.

La afectación a la vida silvestre trasgrede el derecho humano a un ambiente sano de todas las personas, es imperante adecuar la normatividad adjetiva penal y rebasar el marco tradicional de la teoría clásica del interés jurídico para que cualquier individuo tenga legitimación proactiva para la defensa de los derechos ambientales en el sistema penal ambiental a través de una adecuación al CNPP y ampliar el término de la víctima y ofendido en ilícitos ambientales, integrando a organizaciones no gubernamentales con incidencia trascendental en temas relacionados con el ambiente, pueblos y comunidades indígenas, así como a cualquier persona interesada en exigir sus libertades ambientales, garantizando así el acceso a la justicia ambiental ya que en caso contrario se dejaría en un estado de incertidumbre procesal y en un estado de indefensión que puede constituir una violación a las garantías de seguridad jurídica debido a que sin las disposiciones adjetivas procesales de legitimidad procesal no se puede tener un acceso efectivo a la justicia.

Es apremiante fortalecer la participación de la sociedad civil en el combate de los ilícitos contra la biodiversidad y deben de ser el sector más importe en la estrategia de la política pública criminal ambiental, así mismo se debe contar con servidores públicos especializados e instaurar mecanismos anticorrupción en las instituciones publicas ambientales ya que son un factor determinante en la justicia ambiental. 


\section{Bibliografía.}

Alvarado, I. (2011) Conveniencia político-criminológica de la tutela ambiental a través del derecho penal. En Campos, F., Cienfuegos D., Rodríguez L. y Zaragoza, J., Entre libertad y castigo: Dilemas del estado contemporáneo, (pp. 83-99) México: Editora laguna.

Beloff, M. (1994) Lineamientos para una política criminal ecológica. En Maier, J., Delitos no convencionales, (p. 160) Buenos Aires: Editoriales del puerto.

Broswimmer, F. (2005) Ecocidio. Pamplona: Editorial Leatoli.

Butchart, S. et al. (2010) Global Biodiversity: Indicators of Recent Declines. Science, 328 (5982) [pp. 1164-1168].

Ceballos, G. (2008) Naturaleza Mexicana, legado de conservación. México: TELMEX.

Ceballos, G., Salazar, I., List, R., Pacheco, J., y Santos, G. (2006) Vertebrados terrestres. En Cotler, H., Mazari, M., de Anda, J., Atlas de la cuenca Lerma-Chapala, construyendo una visión conjunta.( pp. 24-34) México: Instituto Nacional de Ecología INE-SEMARNAT.

Comisión Económica para América Latina y el Caribe (CEPAL) (2013). Acceso a la información, participación y justicia en temas ambientales en América Latina y el Caribe Situación actual, perspectivas y ejemplos de buenas prácticas. Santiago de Chile: CEPAL.

Comisión para la Cooperación Ambiental (CCA) (2015). El comercio ilegal de flora y fauna silvestres. Perspectiva de América del Norte. Montreal: Comisión para la Cooperación Ambiental.

Coronado, T. (2010). Errores en la procuración y administración de justicia. En: Ruiz, R. (ed.), Errores en la procuración y administración de justicia. México: Instituto Nacional de Ciencias Penales.

Cossío, J., Meza, E. (2013) Delitos contra el ambiente y gestión ambiental en el Código Penal Federal, México: Editorial Bosch.

Cossío, J., Sarukhán, J., Carabias, J. \& Bolívar A. (2014) Defensa legal contra los delitos ambientales. México: Fondo de Cultura Económica.

Chapin III, F. E† al. (2000) Consequences of changing diversity. Nature, 405 (6783) [pp. 234-242].

Dirzo, R., Young, H., Galetti, M., Ceballos, G., Isaac, N. \& Collen, B. (2014) Defaunation in the Anthropocene. Science, 345 (6195) [pp. 401-406].

Fernandez, R. (1995). Elementos para una efectiva protección de los derechos de las víctimas en el proceso penal. Boletín Mexicano de Derecho Comparado. XXVIII (82) [pp. 111 y ss.].

Ferrajoli, L. (2007) Principia iuris. Teoria del diritto e della democracia. Roma: Editori Laterza. 
Ferreres, V. (2002). El principio de taxatividad en materia penal y el valor normativo de la jurisprudencia (Una perspectiva jurisprudencial). Madrid: Editorial Civitas,

Fix-Zamudio, H. (1980). La administración de justicia. Anuario Jurídico. VII. [pp. 69 y ss.].

Haken, J. (2011). Transnational Crime In The Developing World. Recuperado de http://www.gfintegrity.org/wpcontent/uploads/2014/05/gfi_transnational_crime_high-res.pdf

Hassemer, W. (1984). Fundamentos del derecho penal. Barcelona: Editorial Bosch.

Heine, G. (1993). Accesoriedad Administrativa en el Derecho Penal del Medio Ambiente. Anuario de Derecho Penal y Ciencias Penales (ADPCP). Tomo XLVI. Fascículo I. [pp. 289-315].

Henrik, V. W. (1951) Deontic Logic, Mind, (60) [pp. 1-15].

Ibarra, S. (2014). El futuro de la justicia ambiental en México. En varios autores, El futuro de la Justicia Ambiental en México, México: Editorial Miguel Ángel Porrúa.

Martínez de Pisón, J. (1997). Derechos Humanos: Historia, Fundamento y realidad. Zaragoza: Egido Editorial.

Mir Puig, S. (1994). El Derecho penal en el Estado social y democrático de derecho Barcelona: Editorial Ariel.

Nadal, L., Carmona A., Trouyet, M. (2013). Tráfico ilegal de vida silvestre. México: Secretaría de Medio Ambiente y Recursos Naturales.

Nussbaum, M. (2007). Las fronteras de la Justicia. Barcelona: Paidós Ibérica.

Oficina de las Naciones Unidas contra la Droga y el Delito - UNODC (2012). Herramientas para el análisis de los delitos contra la vida silvestre y los bosques, Nueva York: Naciones Unidas.

Ropero, J. (2006). El umedio ambiente como bien jurídico susceptible de protección jurídico penal. Revista Letras Jurídicas. (13) [pp. 2-16].

Sánchez, K. 2012). Breve análisis de la gobernanza en materia de Biodiversidad. En: Carmona, M., Hernández, M. y Acuña, A. 20 años de la procuración de justicia ambiental en México, un homenaje a la creación de la Procuraduría Federal de Protección al Ambiente. (pp.6388) México: Instituto de Investigaciones Jurídicas UNAM.

Sánchez, O., Medellín, R., Aldama, A., Bárbara, G., Soberón, J. y Tambutti M. (2007). Método de evaluación del riesgo de extinción de las especies silvestres en México (MER). México: Instituto Nacional de EcologíaSEMARNAT. 
Sarukhán, J., Carabias, J. Koleff, P. y Urquiza, T. (2012). Capital natural de México: Acciones estratégicas para su valoración, preservación y recuperación, México: CONABIO.

Silva, J. (1992). Aproximación al Derecho Penal contemporáneo, Barcelona, Editorial Bosch.

Steffen, W., Grinevald, J., Crutzen, P. y Mcneill, J. (2011). The Anthropocene: conceptual and historical perspectives. Philosophical transactions of the royal society. 369 (1938) [pp. 842-867].

Valencia, J. (2014). El Acceso a la Justicia Ambiental en Latinoamérica. México: Editorial Porrúa.

Wood, A., Stedman-Edwards, P. y Mang J. (2000). The root causes of Biodiversity Loss. London: Earthscan.

Zimmerman, M. (2003). The black market for wildlife: combating transnational organized crime in the illegal wildlife trade. Vanderbilt Journal of Transnational Law, 36 (5) [pp. 1657-1689].

\section{Normatividad consultada.}

Código Penal Federal. Publicado en el Diario Oficial de la Federación el 14 de agosto de 1931.

Código Nacional de Procedimientos Penales. Publicado en el Diario Oficial de la Federación el 5 de Marzo de 2014.

Conferencia de las Naciones Unidas sobre el Medio Ambiente y el Desarrollo. 3 y el 14 de junio de 1992

Constitución Política de los Estados Unidos Mexicanos. [Const.]. Publicada en el Diario Oficial de la Federación el 5 de Febrero de 1917.

Convención Interamericana para la Protección y Conservación de las Tortugas Marinas. 1 de Diciembre de 1996.

Convención internacional para la reglamentación de la caza de la ballena. 8 de junio de 1937.

Convención Relativa a los Humedales de Importancia Internacional Especialmente como Hábitat de Aves Acuáticas. 2 de Febrero de 1971.

Convención sobre el Comercio Internacional de Especies Amenazadas de Fauna y Flora Silvestres, CITES. 3 de marzo de 1973.

Convenio entre los Estados Unidos Mexicanos y los Estados Unidos de América para la protección de Aves Migratorias y de Mamíferos Cinegéticos. 7 de Febrero de 1936.

Convenio sobre la Diversidad Biológica. 5 de Junio de 1992.

Declaración de las Naciones Unidas sobre el Medio Ambiente.16 de junio de 1972. 
Declaración sobre los principios fundamentales de justicia para las víctimas de delitos y del abuso de poder. 29 de noviembre de 1985.

Declaración Universal de los Derechos Humanos. 10 de diciembre de 1948.

Ley Federal de Responsabilidad Ambiental. Publicada en el Diario Oficial de la Federación el 7 de junio de 2013.

Ley General de Victimas. Publicada en el Diario Oficial de la Federación el 9 de enero de 2013.

Ley General de Vida Silvestre. Publicada en el Diario Oficial de la Federación el 3 de julio del 2000.

Ley General del Equilibrio Ecológico y la Protección al Ambiente. Federación el 28 de enero de 1988.

Protocolo adicional a la Convención Americana sobre Derechos Humanos en materia de derechos económicos, sociales y culturales "Protocolo de San Salvador". 17 de Noviembre de 1988. 